\title{
Turismo rural: perspectivas teóricas e agenda de pesquisa
}

\section{Rural tourism: theoretical perspectives and research agenda}

\section{Cristian Szpanic Bagega}

Graduando em Administração pela Faculdade de Itapiranga - FAl, Itapiranga/SC, Brasil E-mail: cristianbagega@hotmail.com.br

Nathalia Berger Werlang

Professora titular da Faculdade de Itapiranga - FAI, Itapiranga/SC, Brasil

E-mail: nathaliabw@gmail.com 


\section{RESUMO}

O presente estudo tem por objetivo realizar uma pesquisa e mapeamento bibliométrico das publicações sobre Turismo Rural, com o propósito de apresentar dados e indicadores a respeito do tema. A metodologia aplicada para desenvolver a pesquisa foi qualitativa, descritiva, exploratória e análise de conteúdo. A análise dos 59 artigos publicados sobre o Turismo Rural, localizados na base de dados do site Spell, em março de 2017, proporcionou os seguintes resultados: a maioria dos estudos utilizou método qualitativo; os artigos, em sua maior parte, foram elaborados por dois ou três autores; a grande maioria dos autores possui somente uma publicação na área; a Universidade Federal do Rio Grande do Sul (UFRGS) e a Universidade Federal de Santa Maria (UFSM) são as IES de destaque na produção científica sobre o Turismo Rural; os artigos da amostra foram produzidos em maior número no ano de 2011; a Revista Rosa dos Ventos - Turismo e Hospitalidade - é o periódico que se destaca entre as publicações sobre a matéria; a complementação de renda é o tema mais relacionado com o Turismo Rural. Por conta desta pesquisa, tornou-se possível verificar que os estudos científicos sobre Turismo Rural no Brasil são recentes e, por essa razão, não existem muitos trabalhos a respeito; todavia, o desenvolvimento de propriedades rurais por meio do turismo constitui-se um campo muito vasto e crescente. Este estudo visa auxiliar futuras pesquisas, estimulando o debate sobre o tema, em regiões que buscam o desenvolvimento de atividades turísticas.

\section{Palavras-chave: Turismo Rural. Complementação de Renda. Desenvolvimento.} Bibliometria.

\section{ABSTRACT}

The present study has as main purpose to point out a research and a bibliometric mapping of the publications on Rural Tourism, with the objective of presenting data and indicators on the subject. The methodology used to develop the research was qualitative, descriptive, exploratory and content analysis. The analysis of the 59 published articles on Rural Tourism, located in the Spell site database, in March 2017, provided the following results: most of the studies used a qualitative method; The articles, for the most part, were written by two or three authors; The vast majority of authors have only one publication in the area; The Federal University of Rio Grande do Sul (UFRGS) and the Federal University of Santa Maria (UFSM) are the mayoral in scientific production in Rural Tourism; the sample articles of this study were produced in greater number in 2011; the Rosa dos Ventos Magazine - Tourism and Hospitality - is the periodical that stands out among the publications on the subject; The complementation of income is the most related theme on Rural Tourism. Through this research, it became possible to verify that scientific studies on rural tourism in Brazil are recent and, for this reason, there is not much work in this regard; however, the development of rural tourism is vast and growing. This study aims to help future research, stimulating the debate on the theme in regions that seek the development of tourism activities.

Keywords: Rural Tourism. Income Complementation. Development. Bibliometric Studies. 


\section{INTRODUÇÃO}

O crescimento do processo de globalização tem originado diversos impactos na sociedade, podendo destacar as conquistas trabalhistas, que proporcionaram o aumento do tempo livre das pessoas. Diante disso, o segmento de mercado do turismo vem crescendo e se tornando cada vez mais importante na economia (Manosso, Salomé \& Carvalho, 2010). Esse aumento da oferta turística surgiu a partir da intensificação e da diversificação das suas modalidades, mediante a busca e criação de novas formas, produtos e práticas turísticas que atendam à demanda dos consumidores. As segmentações turísticas mais convencionais, como praia e sol, tornaram-se saturadas, o que levou - a partir dos anos 90, a uma segmentação do turismo em novas modalidades turísticas (Candiotto, 2010).

O turismo possui um importante efeito multiplicador na economia, visto que acarreta a elevação da demanda de mão de obra no setor de serviços turísticos, bem como o aumento da procura por produtos locais e maior arrecadação de impostos e taxas. Além da importância econômica, por ser um fenômeno social, o turismo proporciona a troca de experiências, e gera, por meio das suas atividades, múltiplas inter-relações de importância cultural, econômica e social (Lima Filho, Tredezini, Maia \& Santos, 2007).

Deste modo, o processo de globalização tem como resultado o aumento da demanda do Turismo Rural. Essa nova modalidade turística surgiu da necessidade de a sociedade moderna buscar o descanso e o lazer, principalmente por meio da interação com as atividades desenvolvidas no campo. Nesse cenário incluem-se as práticas de lazer nas propriedades rurais, o convívio com as características culturais e técnicas de manuseio da terra, ou seja, os serviços turísticos em contato com a natureza (Manosso, Salomé \& Carvalho, 2010).

Por ser teoricamente novo, esse modelo de turismo possui diversos conceitos, porém, com aspectos semelhantes. O Ministério de Turismo brasileiro, instituição pública que tem como objetivo impulsionar a atividade turística, define o turismo rural como sendo um conjunto de atividades turísticas desenvolvidas no espaço rural, comprometida com as práticas agropecuárias, logo, valoriza os produtos e serviços, possibilitando maior reconhecimento do patrimônio cultural e natural do local (Ministério Do Turismo, 2010).

Destarte, a atividade turística rural surgiu como uma importante alternativa de diversificação econômica. Este segmento cresce gradualmente, e se destaca nas discussões sobre a estratégia de desenvolvimento rural. Essa capacidade de crescer contribui para o processo de desenvolvimento local, que torna o turismo relevante, especialmente para os 
proprietários rurais, uma vez que promove benefícios, principalmente sociais e econômicos (Souza, Elesbão \& Schaidhauer, 2011).

No Brasil, o turismo rural tem se mostrado como uma alternativa econômica, sob o viés de uma oportunidade de minimizar a decadência do meio rural, pois contribui para conservar a atividade agrícola nas propriedades rurais; muitas delas em processo de êxodo rural, devido a fatores de ordem econômica e social (Santos \& Pires, 2010).

Por conta disso, o presente estudo tem como objetivo realizar um mapeamento a respeito do tema Turismo Rural, utilizando como fonte de pesquisa a base de dados Spell. A pesquisa resulta, enfim, na contribuição para a construção de conhecimento cumulativo e idealizado quanto ao tema a fim de possibilitar aos pesquisadores uma estruturação das publicações, além de servir de base para possíveis novos estudos na área.

O presente artigo acadêmico está estruturado em cinco seções: a seção 1 possui caráter introdutório; e logo na seção 2 estão um breve marco teórico acerca do Turismo Rural e os estudos recentes sobre o tema. Dando continuidade, a seção 3 descreve a metodologia utilizada na coleta e análise de dados, e na seção 4 aparecem a descrição e a análise dos resultados do estudo bibliométrico e do mapeamento das publicações citadas na amostra a partir da exposição de quadros e gráficos. Finalizando, a seção 5 traz as considerações finais relativas aos resultados alcançados, e as recomendações para futuras pesquisas.

\section{FUNDAMENTAÇÃO TEÓRICA}

Para introduzir um tema de relevância, faz-se mister um estudo bibliográfico sobre ele. Em função disso, nesse tópico são retratadas as questões teóricas referentes à atividade turística no meio rural, desenvolvidas por meio de abordagens sobre a evolução do turismo rural, seus principais conceitos, a prática do turismo rural com uma alternativa de renda para proprietários rurais e empreendedores e, por fim, uma breve análise dos artigos mais recentes que tratam do tema.

\subsection{Evolução do turismo rural}

Mesmo com poucos trabalhos e áreas de pesquisa sobre Turismo Rural, este tema, em questões práticas, não é novo. Arqueólogos acreditam que na Europa - em algumas das milhares de vilas romanas, já havia atividades de turismo e de lazer. Na Idade Média, inúmeras pessoas com maior poder financeiro detinham alojamentos rurais para as suas 
caçadas. Já nos séculos XVIII e XIX, os europeus da alta classe social construíram grandiosas mansões rurais, cercadas por jardins ornamentais. Apenas a realeza ou proprietários de grandes extensões de terra possuíam palácios rurais. O Turismo Rural, portanto, até há poucos anos, era apenas passatempo da elite privilegiada e não existia para as demais classes sociais (Lane, 2014).

Para acompanhar o acima exposto, Andrade (2012) exemplifica que as práticas do turismo se originaram nas civilizações mais antigas, a partir de diversas atividades, como, por exemplo, as competições esportivas em cidade gregas e as viagens aristocráticas, religiosas, militares e comerciais. O turismo, como atividade econômica, contudo, só começou a ser desenvolvido a partir do século XVIII, na Inglaterra, quando se buscou algo prazeroso nas atividades rurais, no sentido de satisfazer a curiosidade, conhecer novas culturas, aventuras, entre outras mais.

Corroborando, Lane (2014) afirma que o turismo moderno em massa começou a ter crescimento evidente no século XIX, o qual era baseado apenas em sol, mar, areia e entretenimento. O turismo rural moderno, entretanto, surgiu como uma forma emergente em função da procura por um tipo de turismo para as férias, onde não houvesse a presença de multidões, mas sim maior contato com a natureza, com variedades de produtos de nichos, que variam desde tradição à aventura. Tais ofertas de turismo não surgiram por meio do setor privado, bem organizado e informado; pelo contrário, originaram-se a partir de vários pequenos agricultores e empreendedores rurais interessados em obter uma alternativa de renda devido a fatores que vinham prejudicando o rendimento da agricultura. Assim, eles procuravam sobreviver com a diversificação do turismo, a base espontânea de desenvolvimento, nada muito planejado e profissional.

O fenômeno turístico apenas se difundiu em todo o mundo após a sua significativa evolução no século XX. Esta evolução está diretamente ligada a fatores muito importantes, como o aumento do tempo livre das pessoas - uma conquista trabalhista, o avanço tecnológico dos meios de comunicação e transporte, etc. Atualmente, o turismo se apresenta de forma diversificada e com várias tipologias (Manosso, Salomé \& Carvalho, 2010).

Em relação à modalidade do Turismo Rural, nos países europeus essa prática é considerada uma das atividades de destaque, como por exemplo, em Portugal, Alemanha, Itália, França, Espanha, Irlanda. No Brasil, essa atividade ainda é nova e pouco explorada, até porque a maioria dos empreendimentos brasileiros de Turismo Rural segue modelos europeus. 
Já existem, contudo, registros de ideias importadas dos Estados Unidos, influenciadas principalmente pela cultura country (Kloster \& Cunha, 2014).

No Brasil, a primeira iniciativa de Turismo Rural, conforme registros oficiais, ocorreu no ano de 1984, na cidade de Lages (SC). A partir desse primeiro projeto, a atividade vem ganhando cada vez mais importância no cenário rural, com o desenvolvimento de novos empreendimentos e roteiros turísticos em diversas localidades do Brasil. Muitos desses roteiros surgiram por iniciativa dos próprios ruralistas ao perceberem no Turismo Rural uma alternativa de complementação da renda familiar (Pedron, Almeida \& Souza, 2008).

\subsection{Turismo rural: principais conceitos}

Por se tratar de um tema recente no Brasil, o Turismo Rural possui diversos conceitos, os quais evoluíram e se adequaram à realidade das atividades ao longo dos anos. Conforme Tulik (2003), no início o Brasil assimilou conceitos europeus no que se refere à expressão "atividade turística no meio rural”, e emprega, inclusive, as características do agroturismo. Por conta disso, o Turismo Rural adotou conceitos múltiplos, em que várias práticas de turismo foram assimiladas, como por exemplo, turismo interior, turismo diferente, turismo endógeno, turismo verde, os quais podem ser considerados semelhantes ao Turismo Rural. Após a divulgação dessas expressões pela Embratur, em 1994, houve a necessidade de a instituição ordenar e elaborar diretrizes a respeito, propondo a criação de oficinas de Turismo Rural. Posteriormente, em 1998, foi realizada uma nova oficina para identificar problemas recorrentes ao não ordenamento da atividade, e delimitar um novo conceito sobre turismo.

Desde então, diversos conceitos surgiram, decorrentes da ampla discussão sobre o tema, que ganha espaço no cenário brasileiro. Neste sentido, Olga Tulik, uma das autoras vistas como referência na área do Turismo Rural, define em seu livro que o "turismo rural, no escrito senso, deve estar ligado às características próprias do meio rural, excluindo-se desse rótulo outras formas que nada têm a ver com a prática e o conteúdo rural” (Tulik, 2003, p. 43). Desse modo, a autora ressalta que existem diversas abordagens, conceitos e classificações de Turismo Rural, os quais estão sujeitos a vários critérios, e revela a complexidade do assunto.

Araújo (2010, p. 20) define o Turismo Rural como "qualquer atividade de lazer e turismo que seja realizada em áreas rurais, envolvendo, além do agroturismo, outras atividades não relacionadas a propriedades agropecuárias produtivas ou com produção 
agropecuária”. Fomenta também que, para as pessoas ocupadas com atividades agrícolas e que residem no meio rural, o Turismo Rural aparece como uma alternativa de complementação de renda, para que não haja a necessidade de mudança para as cidades (Araújo, 2010).

Da mesma maneira, Andrade (2012) frisa que o Turismo Rural é a atividade praticada no espaço rural, que oferece atividades em meio à natureza para aqueles que vivem em ambientes urbanos, a fim de que possam repor as energias gastas na exaustiva rotina de trabalho, além de conhecer a vida e as atividades praticadas pelo homem do campo.

Já Manosso, Salomé e Carvalho (2010) consideram o Turismo Rural uma atividade que possibilita melhor aproveitamento da propriedade, a fim de agregar valor aos produtos ou serviços realizados no local e gerar mais renda e empregos para as famílias rurais.

Essa percepção é compartilhada por Kloster e Cunha (2014) que ponderam a atividade turística rural como um agente impactante no meio rural, principalmente por proporcionar alternativas de outras fontes de renda para os pequenos produtores rurais. Os recursos podem ser favoráveis para os produtores e também para os agentes privados e entes públicos, que passam a promover investimentos a fim de transformar esses territórios.

Nesse sentido, o Ministério do Turismo define um conceito para todo o território nacional, ou seja: "Turismo Rural é um conjunto de atividades turísticas desenvolvidas no meio rural, comprometido com a produção, agregando valor a produtos e serviços, resgatando e promovendo o patrimônio cultural e natural da comunidade" (Brasil, 2010, p. 18).

À vista disso, verifica-se que o Turismo Rural é uma atividade muita ampla, com diversas áreas para serem exploradas. Por ser uma atividade em meio rural, ela proporciona diversos benefícios, sejam econômicos ou psicológicos, uma vez que proporcionam satisfação aos visitantes que podem desfrutar de aventuras, passeios, culinária e cultura. Essa prática é bastante complexa e deve ser desenvolvida com muito cuidado, planejamento e sustentabilidade, a fim de não prejudicar o meio ambiente local.

\subsection{Turismo rural como fonte de renda}

Nas últimas décadas, o cenário global sofreu diversas mudanças, devido a isso, a oferta de atrativos turísticos se intensifica cada vez mais por meio de diversas modalidades de turismo, e proporciona alternativas de segmentos e a criação de novos produtos/serviços turísticos. Dentre os segmentos que surgem, o Turismo Rural destaca-se, pois, essa prática valoriza os espaços naturais e, pode-se perceber a existência de um melhor aproveitamento 
dos recursos. Teoricamente, essa modalidade de turismo tende a ser mais simples, com uma base já formada, e não proporciona grandes mudanças nas configurações do espaço rural (Candiotto, 2010).

Como uma nova modalidade de turismo, Gallani, Giuliani, Pizzinatto e Correa (2006) salientam que o Turismo Rural é uma importante alternativa de desenvolver uma economia sustentável, haja vista que utiliza os recursos naturais de forma consciente e sem comprometê-los, agregando mais valor à produção da agricultura familiar. Por conta disso, gera avanço no desenvolvimento local e, consequentemente, mais empregos e maior renda para a população que vive no campo. Na realidade, toda a comunidade acaba se beneficiando com as atividades turísticas no meio rural.

A exploração do Turismo Rural tem diversificado a fonte de renda dos produtores rurais, introduzindo uma série de transformações nos hábitos, práticas e valores locais, os quais refletem diretamente na sua situação socioeconômicas (Carlini Júnior, Silva \& Lisboa Filho, 2004).

Deste envolvimento, surgem as novas oportunidades de negócio que, aproveitadas da forma correta, acabam se tornando um empreendimento de sucesso. É necessário, contudo, saber utilizar os recursos rurais, a fim de agregar valor à história, ao percurso étnico, cultural e socioeconômico. A adequação desse patrimônio é algo cativante que atrai interesses de empreendedores rurais e do público visitante. A partir dessas movimentações de pessoas e capital, o Turismo Rural ocasiona - na propriedade - maior produção de alimentos artesanais, bem como a possibilidade de vivência e contato com aspectos históricos e culturais do local, além da proximidade com a natureza. Assim, o Turismo Rural proporciona caminhos para revitalizar a propriedade e inseri-la no contexto social (Fucks \& Souza, 2010).

Esse segmento do turismo possui potencial para tornar-se tendência atual, pois diversifica os interesses de demanda não centrados somente em sol e praia. A mídia - ao divulgar as atividades turísticas, passa a ter papel importante nesse cenário, uma vez que cria uma nova necessidade - com as imagens, por parte dos consumidores. Dessa forma, estimula a procura pelo turismo no meio rural, não apenas entre os consumidores, mas também entre os proprietários, o que os faz refletir sobre uma nova oportunidade de investimento. Essa prática surge como uma forma de desenvolvimento e salvação para o homem do campo, consistindo em um poderoso instrumento de auxílio na preservação das raízes culturais rurais (Fontana, 2010). 
De acordo com o Ministério do Turismo, algumas atividades e serviços oferecidos no meio rural tornam-se essenciais para o sucesso do empreendimento, e alguns podem ser citados: Hospedagem como hotel-fazenda ou pousada; alimentação com almoços e jantares típicos; transporte pela propriedade por meio de passeios de charrete ou trator; atividades de recreação como rapel, tirolesa; pesca esportiva; atividades esportivas; atividades pedagógicas através de atividades de cunho educativo; atividades culturais, etc. (Brasil, 2010).

No entendimento de Gallani, Giuliani, Pizzinatto e Correa (2006), as propriedades que possuem atividades produtivas não necessariamente devem oferecer diversos serviços turísticos, como hospedagem, alimentação típica e comercialização de produtos artesanais locais, mas sim oportunizar aos visitantes que desfrutem de atividades mais ligadas à natureza, como trilhas, diferentes ambientes rurais, e costumes fora do ambiente urbano.

Por meio das transformações do ambiente turístico, o Turismo Rural gera uma reforma na área em que o homem do campo atua, principalmente pela necessidade de comercializar artesanatos, possuir uma culinária típica da região e ter alimentos produzidos naturalmente como, por exemplo, queijos, doces e geleias. Essa transformação proporciona o surgimento de micro e pequenas empresas de serviços rurais, com funções complementares, como receptivos, de artesanato e atividades esportivas e de lazer. Ademais, contribui para a promoção das atividades durante o ano todo, reduzindo a atual sazonalidade (Carlini Júnior, Silva \& Lisboa Filho, 2004).

Apesar dos inúmeros benefícios da atividade turística rural, ela também cria uma nova realidade que provoca impactos no ambiente e, segundo Elesbão (2010), pode gerar situações desagradáveis, como aumento do trânsito de veículos, poluição, eventuais perturbações, dentre outros.

Nessa perspectiva, Andrade (2012) ressalta a importância do manejo correto do espaço rural para fins turísticos, cuja utilização deve ocorrer de forma sustentável, com a intenção de incorporar os princípios e valores éticos. Na maioria das vezes, o ambiente rural é desfrutado como o espaço em que o homem lida com a natureza para satisfazer as suas necessidades e como meio de aprender e adquirir conhecimento sobre a cultura local.

\subsection{Pesquisas recentes sobre o turismo rural}

Apesar de o tema ser teoricamente recente, em questões práticas e científicas no Brasil, vários autores vêm pesquisando sobre o Turismo Rural. Deste modo, a partir de uma pesquisa bibliométrica, foram identificados - dentre os trabalhos que compõem a base de 
dados desta pesquisa, alguns estudos mais recentes acerca do tema, os quais passam a ser apresentados a seguir.

Nesse contexto, o estudo de Azevedo e Rodrigues (2015) objetiva analisar e problematizar as potencialidades e desafios do Turismo Rural no município de Apodi (RN), com o propósito de considerar as possíveis interfaces entre a agricultura familiar e o turismo, entre outros programas de auxílio, como o Pronaf e o Programa de Regionalização do Turismo, doravante escrito como PRT. Para realizar esta análise adotou-se o estudo de caso como estratégia de pesquisa, mediante uma amostra de 13 entrevistados. A partir das análises foi possível verificar que o Pronaf tem promovido o desenvolvimento da agricultura familiar, bem como a obtenção de melhores condições no campo. Já o PRT não identificou qualquer ação que favoreça o desenvolvimento do turismo, nem mesmo planos de desenvolvimento, com ações planejadas em nível local. A implantação do turismo local está ocorrendo, todavia, de duas maneiras diferentes - a primeira de forma isolada, realizada por empresas privadas, e a segunda por meio de cooperativas e ONGs.

Vale destacar, também, a pesquisa de Maia (2016), que buscou analisar aspectos sobre o Turismo Rural, no sentido de saber se esse segmento pode ser um promotor de desenvolvimento local no Assentamento Tijuca Boa Vista, em Quixadá, no Estado do Ceará, de modo a destacar os eventuais impactos econômicos e sociais oriundos da sua implantação no local. A pesquisa adotou a prática de um estudo de caso com a participação de 21 entrevistados, dos quais 19 eram integrantes das famílias do local e três eram gerentes de pousadas. Após a análise dos resultados concluiu-se que a atividade turística rural possui grande possibilidade de complementar a renda local mediante a criação de muitos postos de trabalho e diversificação da economia local. O Turismo Rural, no entanto, não pode ser considerado um promotor de desenvolvimento local, uma vez que a atividade não conseguiu se consolidar no local.

Diante do exposto, foi possível perceber que há aspectos semelhantes e diferentes conceitos sobre o Turismo Rural entre os autores pesquisados. A maioria dos estudos abordou o Turismo Rural como uma forma de desenvolvimento local, gerando novas alternativas de renda, criando formas de valorizar o espaço rural, trazendo a cultura e a diversidade para os visitantes. Desta maneira, pode-se perceber que não há dúvida sobre a importância do Turismo Rural para os proprietários rurais, gerando inúmeros benefícios e proporcionando boas perspectivas no meio rural. 


\section{MÉTODO E PROCEDIMENTOS DE PESQUISA}

O presente estudo acadêmico constitui-se de uma pesquisa qualitativa, descritiva e exploratória. Qualitativa pois parte de uma coleta de dados com o objetivo de elaborar uma definição básica sobre o tema, de modo a analisar as suas particularidades (Marconi \& Lakatos, 2004); descritiva por ter como propósito a descrição das características, levantamento e interpretação de dados e indicadores a respeito de publicações científicas sobre o Turismo Rural; exploratória por analisar a área do Turismo Rural no atual contexto, mediante pesquisa bibliométrica e mapeamento das publicações da amostra, o que permite obter uma perspectiva sobre a área objeto de estudo, de modo a possibilitar a consideração de variados aspectos sobre a atividade turística no espaço rural (Gil, 2002).

$\mathrm{Na}$ sequência foram utilizadas técnicas de pesquisa bibliométrica e análise de conteúdo. A pesquisa bibliométrica corresponde a uma análise das atividades científicas ou técnicas por meio dos estudos quantitativos das publicações. Desta forma, os dados quantitativos calculados com base nas contagens estatísticas de publicações ou de elementos que agrupam técnicas estatísticas visam quantificar os procedimentos de comunicação escrita (Silva, Hayashi \& Hayashi, 2011). A pesquisa bibliométrica representa um modelo de pesquisa que pode ser utilizado para mapear produções científicas em determinada área de conhecimento a partir de métodos matemáticos e estatísticos (Silva, Machado \& Catapan, 2014).

O objeto de estudo desta pesquisa tem por base os artigos científicos sobre o Turismo Rural, disponíveis na base de dados do site Spell, cuja investigação foi realizada no dia 02 de março de 2017, mediante a inserção da expressão “Turismo Rural”. Foram encontrados 61 trabalhos, nacionais e internacionais, com a utilização do filtro "somente artigos", sendo 59 da área de estudos da Administração, publicados no período de 1994 a 2016.

A Tabela 1, a seguir, representa, de forma lacônica, os filtros utilizados para obter a amostra dos artigos encontrados.

Tabela 1. Filtros utilizados na amostra

\begin{tabular}{lc}
\hline \multicolumn{1}{c}{ Base de dados Spell } & Total de trabalhos \\
\hline Palavra-chave "Turismo Rural” & 61 \\
Filtro "somente artigos" & 59 \\
Área de conhecimento "Administração" & 59 \\
\hline Total & $\mathbf{5 9}$ \\
\hline
\end{tabular}

Fonte: Dados da Pesquisa (2017). 
Com o objetivo de analisar e expressar alguns dados acerca do Turismo Rural, averiguou-se a natureza das pesquisas, a fonte de coleta de dados, as múltiplas abordagens a respeito do tema objeto de estudo, a metodologia dos trabalhos, o número e gêneros de autores, autores com mais publicações na área, as instituições que mais publicam, os principais periódicos, os construtos relacionados, as estratégias de estudo e demais dados.

$\mathrm{Na}$ fase de mapeamento, posteriormente agrupados e organizados, os 59 artigos foram submetidos a uma análise, do modo que as informações extraídas auxiliassem na composição de uma ficha classificatória. A técnica utilizada foi a análise de conteúdo, que visa obter os procedimentos sistemáticos e objetivos, a descrição do conteúdo/informações qualitativos ou não, a fim de compreender os conhecimentos relativos às condições variáveis (Bardin, 2011).

\section{DESCRIÇÃO E ANÁLISE DOS RESULTADOS}

Por meio da análise dos 59 artigos encontrados, foi possível realizar um mapeamento dos dados, os quais passam a ser demonstrados por meio de descrições, tabelas e gráficos. Inicialmente, a Tabela 2 apresenta os principais autores que, dentre a amostra do estudo, tiveram maior contribuição nas pesquisas.

Tabela 2. Autores que mais contribuíram nas pesquisas

\begin{tabular}{lcr}
\hline \multicolumn{1}{c}{ Autor } & Quant. de publicações & \% \\
\hline Marcelino de Souza & 6 & 4,29 \\
Raquel Lunardi & 3 & 2,14 \\
Lilia Zizumbo Villarreal & 3 & 2,14 \\
Joaquim Anécio Almeida & 3 & 2,14 \\
Demais autores com duas (2) publicações & 10 & 7,14 \\
Demais autores com uma (1) publicação & 115 & 82,15 \\
\hline Total & $\mathbf{1 4 0}$ & $\mathbf{1 0 0 , 0 0}$ \\
\hline
\end{tabular}

Fonte: Dados da Pesquisa (2017).

Com base na Tabela 2, verificou-se que Marcelino de Souza é o autor que detém o maior número de publicações acerca do tema Turismo Rural, com seis artigos publicados, correspondendo a 4,29\%; seguido de Raquel Lunardi; Lilia Zizumbo Villarreal e Joaquim Anécio de Almeida, cada um com três publicações, equivalendo 2,14\%.

Souza é professor associado do Departamento de Economia e Relações Internacionais e dos Programas de Pós-Graduação em Desenvolvimento Rural e de Agronegócio da Universidade Federal do Rio Grande do Sul (UFRGS). Atualmente participa 
de projetos de pesquisa nas áreas turísticas da Serra Gaúcha e de estratégias de desenvolvimento rural, destacando-se como o autor que mais publicou artigos nesta área.

Em seguida constam os três autores - Lunardi, Villarreal e Almeida - cada um com três publicações. Lunardi é professora no Instituto Federal Farroupilha (IFF), possui experiência na área turística, atuando em temas como o papel da mulher, turismo rural, desenvolvimento rural, entre outros. Villarreal possui licenciatura em Turismo e doutorado em Sociologia pela Universidade Nacional Autônoma do México (UNAM). Atualmente trabalha como investigadora de estudos turísticos junto à Universidade Autônoma do Estado do México (UAEMex). Por fim, Almeida é professor na Universidade Federal de Santa Maria (UFSM), e possui experiência na área de Agronomia, com ênfase em extensão rural.

Dentre esses principais autores, apenas Villarreal não possui nenhuma conexão com os demais, todavia, Souza, Almeida e Lunardi possuem ligações. Souza escreveu dois artigos em parceria com Lunardi, nos quais abordam temas a respeito da participação do homem e da mulher na área turística rural e na tomada de decisão a partir das perspectivas de gêneros. Além disso, Souza possui dois artigos publicados em parceria com Almeida, apresentando alguns processos de planejamento para a implantação de um roteiro turístico rural. Finalmente, Almeida dispõe de uma publicação em conjunto com Lunardi, em que discorrem acerca da contribuição da mulher na prática turística rural.

A seguir, a Tabela 3 destaca as abordagens metodológicas utilizadas nos artigos que constituíram as bases do estudo, as quais foram classificadas em qualitativa, quantitativa, quali-quantitativa e de revisão bibliográfica.

Tabela 3. Classificação dos artigos por abordagem metodológica

\begin{tabular}{lcc}
\hline \multicolumn{1}{c}{ Abordagem } & Quant. de publicações & \% \\
\hline Artigos Qualitativos & 31 & 52,54 \\
Artigos de Revisão Bibliográfica & 23 & 38,98 \\
Artigos Quantitativos & 2 & 3,39 \\
Artigos Quali-Quantitativos & 3 & 5,09 \\
\hline Total & $\mathbf{5 9}$ & $\mathbf{1 0 0 , 0 0}$ \\
\hline
\end{tabular}

Fonte: Dados da Pesquisa (2017).

Verifica-se, a partir da Tabela 3, que a abordagem de pesquisa mais utilizada se caracteriza como qualitativa $(52,54 \%)$, sendo que a estratégia de pesquisa utilizada em 28 artigos ocorre por meio de estudos de caso e os demais referem-se a grupo focal, pesquisa netnográfica e pesquisa etnográfica. 
A segunda abordagem de pesquisa mais utilizada foi a de Revisão Bibliográfica, representando 38,98\%, dentre os quais 23 empregaram a estratégia de pesquisas bibliográficas.

A abordagem de pesquisa quantitativa está presente em duas publicações, representando $3,39 \%$ dos artigos, tendo como estratégia de pesquisa empregada o levantamento de dados em survey. No método de abordagem quali-quantitativo foram encontradas três publicações, o que corresponde a 5,08\% dos trabalhos. Nesta abordagem estratégica de pesquisa, dois artigos dizem respeito a um estudo de caso e outro artigo possui análise exploratória e teste Qui-Quadrado.

Em relação aos métodos, foi possível perceber que a estratégia de pesquisa qualitativa se destaca entre os demais. Esta situação pode ser explicada pelo fato de a grande maioria dos estudos focar em situações isoladas acerca de uma determinada propriedade, um roteiro e/ou uma região específica. Do mesmo modo, é necessário ressaltar que ainda não há regiões que possuem muitas propriedades que usufruem dessa prática, não existem aglomerados nesta área de Turismo Rural e, por esse motivo, a maioria dos estudos se baseia em casos específicos, com uma amostra menor.

Vale destacar que dos 59 artigos somente um (01) contou com o instrumento de coleta de dados, e se referia a um estudo qualitativo. Além disso, dentre todos os artigos analisados, apenas um (01) apresentou o autor-modelo, o que se deve ao fato de o tema ser relativamente recente no Brasil e não existirem muitos estudos na área. Quanto às Instituições de Ensino Superior que mais se destacam, a Tabela 4 apresenta o seu ordenamento de acordo com o número de publicações.

Tabela 4. Quantidade de publicações por Instituição de Ensino Superior

\begin{tabular}{lcc}
\hline \multicolumn{1}{c}{ Instituições de Ensino Superior } & Quant. de publicações & \% \\
\hline Universidade Federal do Estado do RS & 7 & 7,78 \\
Universidade Federal de Santa Maria & 7 & 7,78 \\
Universidade Autônoma del Estado del México & 4 & 4,44 \\
Universidade de São Paulo & 4 & 4,44 \\
Universidade de Caxias do Sul & 3 & 3,33 \\
Universidade Federal Rural de Pernambuco & 3 & 3,33 \\
Universidade do Vale de Itajaí & 3 & 3,33 \\
Outras IES (2) & 22 & 24,45 \\
Outras IES (1) & 37 & 41,12 \\
\hline Total & $\mathbf{9 0}$ & $\mathbf{1 0 0 , 0 0}$ \\
\hline
\end{tabular}

Fonte: Dados da Pesquisa (2017).

A respeito das principais Instituições de Ensino Superior, a Tabela 4 destaca a Universidade Federal do Rio Grande do Sul (UFRGS) e a Universidade Federal de Santa 
Maria (UFSM) como as que mais publicaram artigos sobre o tema, com sete (07) publicações cada uma. Todavia, elas não oferecem nenhum curso no ramo turístico. A UFRGS, contudo, registra cursos de doutorado na área de Desenvolvimento Rural e Desenvolvimento Rural Interinstitucional, e a UFSM oferece cursos de pós-graduação em Extensão Rural e doutorado em Extensão Rural. É valido ressaltar, também que, entre os quatros principais autores três (03) possuem ligação direta com estas instituições, seja como professor, ou mesmo como estudante. Souza e Almeida são, até os dias atuais, professores da UFRGS e UFSM respectivamente, e Lunardi por sua vez, estudou nas duas instituições.

Em segundo lugar, a Universidade Autônoma del Estado do México (UAEMex) e a Universidade de São Paulo (USP) destacam-se como as IES que mais publicaram artigos na área do Turismo Rural, contando com quatro publicações cada uma. A UAEMex disponibiliza cursos de graduação em Turismo, mestrado e doutorado em Ciências Agrárias e Desenvolvimento Rural, os quais estão inter-relacionados com o tema. A USP, por sua vez, oferece o curso de graduação e pós-graduação em Turismo, bem como outros cursos correlacionados à área de Ciências Agrárias e projetos de pesquisa em Desenvolvimento Rural.

Por fim, em terceiro lugar entre as IES, com três artigos publicados cada uma, destacam-se a Universidade de Caxias do Sul (UCS), a Universidade Federal Rural de Pernambuco (UFRPE) e a Universidade do Vale do Itajaí (Univali). A primeira conta com cursos de graduação em Turismo, mestrado e doutorado em Turismo e Hospitalidade; a segunda não oferece cursos ligados à área turística, contudo, tem mais ênfase no âmbito rural; e a terceira IES dispõe de cursos de graduação, mestrado e doutorado em Turismo e Hotelaria.

Outro dado relevante para este estudo são os principais periódicos que tratam do Turismo Rural, cujas informações estão relatadas na Tabela 5, a seguir.

Tabela 5. Principais periódicos que tratam do Turismo Rural

\begin{tabular}{lcc}
\hline \multicolumn{1}{c}{ Nome dos periódicos } & Quant. de publicações & \% \\
\hline Rosa dos Ventos - Turismo e Hospitalidade & 13 & 22,03 \\
Turismo: Visão e Ação & 9 & 15,25 \\
Caderno Virtual de Turismo & 9 & 15,25 \\
Turismo em Análise & 8 & 13,56 \\
Revista Acadêmica do Observatório de Inovação do & & 8,47 \\
Turismo & 5 & 5,08 \\
Revista Brasileira de Pesquisa em Turismo & 3 & 6,78 \\
Outros periódicos (2) & 4 & 13,56 \\
Outros periódicos (1) & 8 & $\mathbf{1 0 0 , 0 0}$ \\
\hline Total & $\mathbf{5 9}$ & \\
\hline
\end{tabular}

Fonte: Dados da Pesquisa (2017). 
A Tabela 5 destaca a Revista Rosa dos Ventos - Turismo e Hospitalidade como o periódico que mais publicou artigos sobre Turismo Rural, constituindo-se no maior percentual da amostra, com 22,03\%. Este periódico dedica-se à reflexão e discussão sobre o turismo e hospitalidade, com foco na gestão, cultura, meio ambiente e educação. Seu escopo foi definido a partir de uma visão multidisciplinar do fenômeno turístico, que reconhece suas implicações nas variáveis da gestão ambiental, pela economia, pela inovação, entre outras.

Em seguida aparecem as revistas Turismo: Visão e Ação e Caderno Virtual de Turismo, com nove (09) publicações cada uma; o periódico Turismo em Análise, com oito (08) artigos; a revista Acadêmica do Observatório de Inovação do Turismo, com cinco (05) publicações, e a Revista Brasileira de Pesquisa em Turismo, com três (03) artigos publicados. É importante salientar, contudo, que periódicos com duas e com uma publicação constituem, respectivamente, $6,78 \%$ e $13,56 \%$ do total.

Com base nesses dados, constatou-se uma correlação entre os principais periódicos e os autores que mais se destacam, sendo que quatro publicações da Revista Rosa dos Ventos Turismo e Hospitalidade, estão diretamente ligadas a Souza com uma (01) publicação e Villarreal com três (03) periódicos. Outro exemplo é a Revista Turismo em Análise que possui dois (02) periódicos produzidos por Souza.

Constata-se que há uma elevada diferença quanto ao número de publicações entre os principais periódicos, uma vez que alguns se sobressaem em relação aos outros. Vale destacar, contudo, que apesar da diferença numérica dos principais periódicos, todos estão voltados à área turística, apresentando uma ampla visão do fenômeno turístico.

Em relação aos anos das publicações, o Gráfico 1, a seguir, apresenta a evolução do número de publicações no decorrer do tempo.

Pela amostragem do Gráfico 1, percebe-se que há uma constante evolução e desenvolvimento de estudos sobre a atividade turística rural. A partir desses dados, é possível identificar o crescente aumento do número de publicações sobre o tema ao longo dos anos, principalmente a partir de 2006. 
Gráfico 1. Quantidade de publicações por ano

Quantidade de publicações por ano

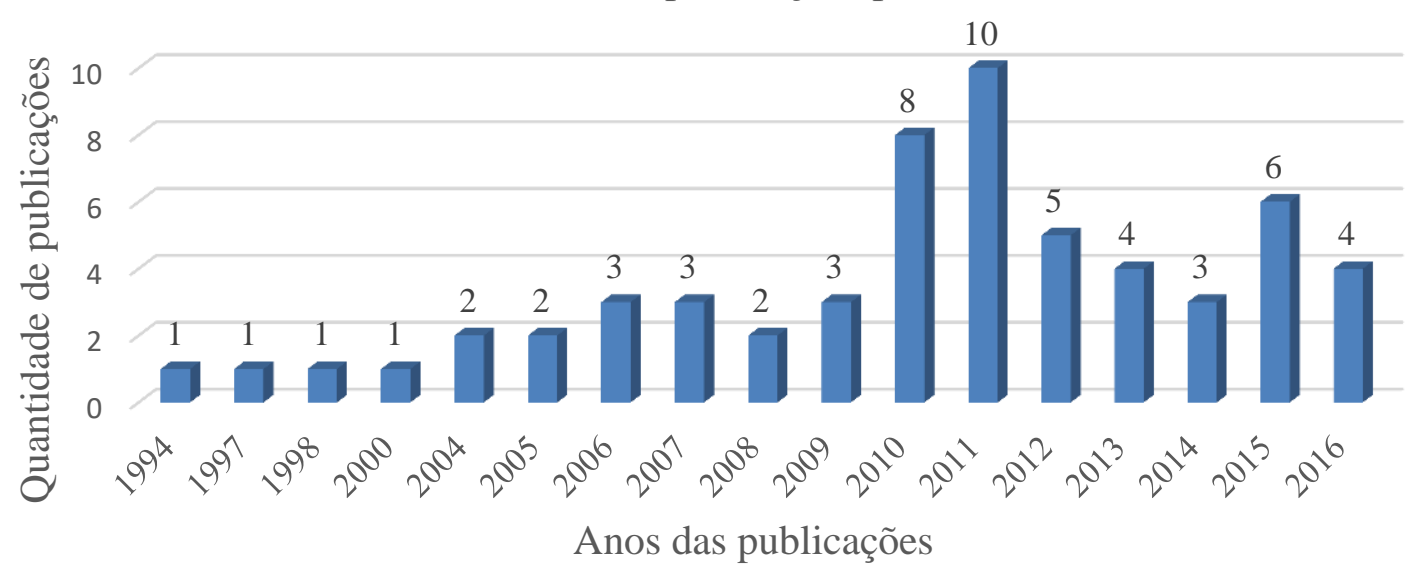

Fonte: Dados da Pesquisa (2017).

A respeito dos anos de publicação dos artigos que constituíram a base deste estudo, observou-se que o ano de 2011 foi o período em que mais foram publicados trabalhos, em um total de onze (11) artigos. Em seguida constam os anos 2010, 2015, 2012, respectivamente com oito (08), seis (06) e cinco (05) publicações. Os dados confirmam a relevância e a importância que os estudiosos têm dado ao tema, considerando as eventuais mudanças e possiblidades da atual situação. Na sequência, a Tabela 6 demonstra os principais construtos utilizados nos artigos, objeto deste estudo.

Tabela 6. Principais construtos utilizados nos artigos selecionados

Complementação de renda

\section{Construtos}

Desenvolvimento local Quant. de publicações

Atividade turística

Desenvolvimento turístico

Agricultura familiar

\begin{tabular}{rr}
10 & 4,93 \\
8 & 3,94 \\
6 & 2,96 \\
5 & 2,46 \\
4 & 1,97 \\
170 & 87,74 \\
$\mathbf{2 0 3}$ & $\mathbf{1 0 0 , 0 0}$ \\
\hline
\end{tabular}

Total

203

Fonte: Dados da Pesquisa (2017).

A respeito dos construtos utilizados nos artigos selecionados, a Tabela 6 apresenta a "complementação de renda" como o mais utilizado, constando em 10 ocasiões, o que corresponde a 4,93\%. Isso explica o fato de que grande parte dos estudos remete à atividade turística rural como uma alternativa de melhora da renda dos proprietários rurais, constituindo-se em uma fonte de renda secundária. $\mathrm{O}$ "desenvolvimento local" foi o construto que apareceu em oito oportunidades $(3,59 \%)$, confirmando que o Turismo Rural proporciona 
inúmeros benefícios tanto aos proprietários como para a comunidade em que o roteiro está inserido.

O construto "atividade turística" destaca-se como o terceiro mais citado, aparecendo em seis publicações $(2,69 \%)$. O termo comprova que a prática turística rural e a procura por ambientes em meio à natureza vêm ganhando espaço em relação às demais atividades turísticas. Em quarto lugar está o "desenvolvimento turístico”, com cinco utilizações (2,24\%), o que mostra que - apesar de a atividade turística ser teoricamente uma prática não muito complexa, se não houver planejamento e manejo adequado, a possibilidade de ser um negócio de curto prazo de duração é bastante elevada. Por fim, o construto "agricultura familiar" destaca-se em quatro momentos, principalmente pelo fato de que, em alguns estudos, os autores focam na questão da melhoria da situação familiar dos agricultores, a fim de proporcionar uma alternativa de renda, e valorizar os produtos e o trabalho do homem do campo. Mantêm, contudo, os seus hábitos e culturas adaptadas às situações ambientais.

Pelo fato de o tema ainda ser recente e não existirem muitas pesquisas a respeito, não foram encontrados muitos autores-modelos, sendo que a grande maioria dos trabalhos se fundamenta em teorias e estudos com pequenas amostras de respondentes. Com o aumento da oferta e demanda por esse tipo de turismo, todavia, futuramente serão possíveis novos empreendimentos, uma vez que as pesquisas sobre o tema tenderão a ser mais precisas e com maior amostragem, podendo proporcionar uma análise mais ampla da situação.

No que concerne às indicações de futuros estudos, a grande maioria dos artigos não apresentou sugestões futuras, uma vez que foca em casos específicos, isto é, no estudo de uma determinada situação, e não em um contexto com maior amostragem.

O Quadro 1, a seguir, retrata os principais indicadores de futuras pesquisas na área do Turismo Rural.

Quadro 1. Indicações de futuros estudos na área do Turismo Rural

\begin{tabular}{|l|l|}
\hline \multicolumn{1}{|c|}{ Indicações de estudo } & \multicolumn{1}{|c|}{ Autor (ano) } \\
\hline $\begin{array}{l}\text { Aprofundar a investigação sobre elementos que facilitem ou impeçam a } \\
\text { cooperação em modelos de aglomerados de Turismo Rural }\end{array}$ & Czajkowsi e Cunha (2010) \\
\hline $\begin{array}{l}\text { Realizar pesquisas cujo método de coleta de dados seja a observação } \\
\text { participante de três etapas: planejamento, execução e avaliação }\end{array}$ & $\begin{array}{l}\text { Reis e Vavassori } \\
(2013)\end{array}$ \\
\hline $\begin{array}{l}\text { A fim de compreender as atitudes e comportamentos dos promotores de } \\
\text { Turismo Rural, é interessante realizar estudos com uma análise mais } \\
\text { qualitativa por meio da triangulação de dados }\end{array}$ & Pato (2015) \\
\hline $\begin{array}{l}\text { Apresentar o cenário da governança regional no contexto da sustentabilidade, } \\
\text { que pode influenciar na continuidade efetiva dos empreendimentos rurais }\end{array}$ & Sanches e Schmidt (2016) \\
\hline $\begin{array}{l}\text { Desenvolver maior número de pesquisas sobre festas tradicionais com o } \\
\text { objetivo de compreender a importância do Turismo Rural na valorização de } \\
\text { pequenas comunidades }\end{array}$ & $\begin{array}{l}\text { Reis e Teixeira } \\
\text { (2016) }\end{array}$ \\
\hline
\end{tabular}

Fonte: Dados da Pesquisa (2017). 
Dentre as indicações apresentadas, é possível perceber que todas remetem a sugestões distintas, por meio de casos específicos de determinadas regiões, de modelos de aglomerados e gestão de redes de cooperação ou de valorização das pequenas comunidades por meio do turismo com festas tradicionais.

Finalmente, após demonstrar vários dados e informações na etapa da apresentação dos resultados e análises, o tópico a seguir apresenta as principais considerações em relação ao estudo efetuado.

\section{CONSIDERAÇÕES FINAIS}

O presente estudo objetivou apresentar um mapeamento bibliométrico acerca das produções científicas sobre Turismo Rural. Nesse sentido, foi realizado um estudo sistemático das publicações a respeito do tema, disponíveis na base de dados Spell, em março de 2017, com uma amostra de 59 artigos nacionais e estrangeiros.

Quanto aos dados da pesquisa bibliométrica é necessário ressaltar que se encontrou uma diversidade de autores e de estudos sobre o tema, principalmente em razão de os estudos nesta área serem teoricamente recentes. $\mathrm{Na}$ fase de mapeamento foram desenvolvidas as seguintes etapas de pesquisa: principais autores; abordagem metodológica dos artigos; artigos com instrumento de coleta de dados; Instituições de Ensino Superior em destaque; principais periódicos; agrupamento dos anos das publicações; construtos mais citados e, por fim, as sugestões para futuros estudos relativos ao tema.

Em relação aos autores, somente Souza se destacou em relação aos demais, apresentando seis (06) publicações, todavia, a grande maioria dos autores $(82,15 \%)$ teve apenas uma (01) publicação. Quanto aos métodos de pesquisa, identificou-se a superioridade dos métodos qualitativos e de revisão bibliográfica, utilizados em 52,54\% e 38,98\% dos estudos, respectivamente. Isso explica o fato de que os estudos sobre Turismo Rural são realizados, em sua grande maioria, em casos específicos, em um lugar ou um roteiro.

Com relação às Instituições de Ensino Superior, a Universidade Federal do Rio Grande do Sul (UFRGS) e a Universidade Federal de Santa Maria (UFSM) são as que se destacam na produção científica sobre o Turismo Rural, com sete (07) artigos cada uma, representado $15,56 \%$ do total das IES. A maior parte dos artigos da amostra foi publicada no ano de 2011, em um total de onze (11) artigos. Seguido pelos anos de 2010, 2015, 2012, respectivamente com oito (08), seis (06) e cinco (05) artigos publicados. 
A respeito dos periódicos que mais publicaram, a Revista Rosa dos Ventos Turismo e Hospitalidade é a que se destaca, com treze (13) publicações, representando $23,03 \%$, sendo que quatro artigos possuem autoria de três dos principais autores. Entre os construtos identificados e relacionados ao Turismo Rural, a "complementação de renda" é o mais utilizado, constatado em 4,93\% dos estudos. Em seguida, em oito oportunidades $(3,94 \%)$ consta o "desenvolvimento local", seguido da "atividade turística", em seis (2,96\%) ocasiões; “desenvolvimento turístico", em cinco $(2,46 \%)$ ocasiões; "agricultura familiar", em quatro $(1,97 \%)$ ocasiões, e os demais construtos, em um total de 170 identificações, representam $87,14 \%$.

Diante do exposto, pode-se considerar que os estudos acerca do turismo rural ainda são incipientes no Brasil, e começaram a se desenvolver com maior intensidade a partir dos anos 2010, sendo que os estudos focam em compreender principalmente como o turismo pode contribuir com o desenvolvimento das regiões por meio da sua contribuição econômica.

Assim, verifica-se que os estudos de caso se apresentam como maioria nas estratégias de pesquisa adotadas pelos autores, e sugere-se que este ainda seja o método adotado para novos estudos que precisam ser desenvolvidos, a fim de compreender a partir de novas evidências, como os municípios se organizam para desenvolver o turismo em termos de empresas privadas, comunidade e governo.

É possível inferir que o turismo como principal fonte de renda ocorre em cidades que já possuem recursos naturais abundantes de modo que ele se desenvolva espontaneamente. Entretanto, foram evidenciados outros estudos que destacam como alguns municípios criaram atrativos turísticos, principalmente junto a propriedades rurais, e desenvolveram a atividade para que esta auxiliasse no desenvolvimento da região, como um complemento de renda da população. Relaciona-se a isso, o fato da crise econômica do Brasil em 2008, visto que a partir dos anos de 2010 surgiram mais estudos de caso que apontam o turismo como fator importante para a economia.

Por fim, como indicação de futuros estudos, sugere-se que novos estudos procurem compreender como determinadas comunidades se organizam para fomentar o turismo. É interessante aprofundar os estudos que analisam aglomerados do Turismo Rural, compreender como as festas tradicionais das comunidades impactam no turismo, entre outros.

Entende-se que o presente estudo possui suas limitações, principalmente por usufruir apenas de uma base de dados para análise (site Spell), o que se torna um fator limitador. Quiçá, se poderia lograr um resultado diferente se houvesse uma maior amostra. Da mesma 
forma, por ter sua base apenas em artigos, percebeu-se a necessidade da busca em outros meios para complementar o estudo. Constatou-se, por fim que - mesmo havendo limitações, o método utilizado foi suficiente para alcançar o objetivo da pesquisa.

\section{REFERÊNCIAS}

Andrade, D. (2012). Turismo rural: análise dos resultados de um projeto de extensão no âmbito da comunidade. Revista Acadêmica do Observatório de Inovação do Turismo, 7(2), 69-80.

Araújo, J. G. F. (2010). Potencialidades do turismo no espaço rural: desenvolvimento, conceitos e tipologia. In: Santos, E. O., \& Souza, M. (Orgs.). Teoria e prática do turismo no espaço rural, 23-32. Barueri, SP: Manole.

Azevedo, R. M. M., \& Rodrigues, C. G. O. (2015). Políticas públicas e turismo rural: um estudo acerca das possibilidades e limitações no município de Apodi (RN). Caderno Virtual de Turismo, 15(2), 131-145.

Bardin, L. (2011). Análise de conteúdo. São Paulo: Edições 70.

Brasil. (2010). Secretaria Nacional de Políticas de Turismo. Departamento de Estruturação, Articulação e Ordenamento Turístico. Coordenação Geral de Segmentação. Turismo rural: orientações básicas. (2a. ed.). Brasília: Ministério do Turismo.

Candiotto, L. Z. P. (2010). Elementos para o debate acerca do conceito de turismo rural. Turismo em Análise, 21(1), 3-24.

Carlini Júnior, R. J., Silva, F. J., \& Lisboa Filho, W. (2004). A pluriatividade na Zona da Mata de Pernambuco: o turismo rural como uma viável alternativa econômica. Revista Brasileira de Gestão de Negócios, 6(16), 7-14.

Elesbão, I. (2010). Impactos socioeconômicos do turismo no espaço rural. In: Santos, E. O., \& Souza, M. (Orgs.). Teoria e prática do turismo no espaço rural. Barueri, SP: Manole, 150169.

Fontana, R. F. (2010). Inovação no planejamento do turismo e da hospitalidade no espaço rural. In: Santos, E. O., \& Souza, M. (Orgs.). Teoria e prática do turismo no espaço rural, 259-275. Barueri, SP: Manole.

Fucks, P. M., \& Souza, M. (2010). Turismo no espaço rural e preservação do patrimônio, da paisagem e da cultura. In: Santos, E. O., \& Souza, M. (Orgs.). Teoria e prática do turismo no espaço rural, 96-108. Barueri, SP: Manole.

Gallani, M. A., Giuliani, A. C., Pizzinatto, N. K., \& Correa, D. A. (2006). O turismo rural da cidade de Piracicaba e sua expansão utilizando-se as ferramentas do planejamento estratégico contempladas no Projeto Piracicaba. Revista Ciências Administrativas, 12(2), 186-190.

Gil, A. C. (2002). Como elaborar projetos de pesquisas. (4a. ed.). São Paulo: Atlas. 
Kloster, S., \& Cunha, L. A. G. (2014). Desenvolvimento territorial e turismo rural: as relações possíveis. Desenvolvimento em questão, 12(27), 66-94.

Lane, B. (2014). Turismo rural de segunda geração: prioridades e questões de pesquisa. Turismo rural: antecedentes. In: Cristovão, A. et al. (Orgs.). Turismo rural em tempos de novas ruralidades, 15-48. Porto Alegre: Ed. da UFRGS.

Lima Filho, D. O., Tredezini, C. A. O., Maia, F. S., \& Santos, A. M. (2007). O turismo rural como alternativa econômica para a pequena propriedade rural no Brasil. Turismo: Visão e Ação, 9(1), 69-82.

Lunardi, R., Souza, M., \& Perurena, F. (2015). O trabalho de homens e mulheres no turismo rural em São José dos Ausentes: o "leve" e o "pesado". Turismo: Visão e Ação, 17(1), 179209.

Maia, E. M. M. (2016). Turismo rural na agricultura familiar: um estudo de caso no assentamento Tijuca, Boa Vista em Quixadá (CE). Caderno Virtual de Turismo, 15(1), 1-19.

Manosso, F. C., Salomé, M. V., \& Carvalho, A. T. (2010). Turismo rural na região Norte do Estado do Paraná: conceito e prática. Caderno Virtual de Turismo, 10(1), 24-35.

Marconi, M. A., \& Lakatos, E. M. (2004). Fundamentos de metodologia científica. (4a. ed.). São Paulo: Atlas.

Pato, M. L. J. (2015). O modesto contributo do turismo rural no Douro, Portugal: um estudo baseado nos promotores e na oferta turística. Turismo em Análise, 27(3), 624-643.

Pedron, F. A., Almeida, J. A., \& Souza, M. (2008). Avaliação do planejamento do turismo rural no roteiro Nostra Colonia, Jaguari - RS. Turismo: Visão e Ação, 10(2) 263-285.

Reis, J. M. D., \& Teixeira, J. (2016). Festas tradicionais no entorno da Estrada Boiadeira no Paraná: um potencial para o turismo rural. Turismo em Análise, 27(2), 364-387.

Santos, A. S., \& Pires, P; S. (2010). Políticas públicas de turismo rural: uma alternativa necessária. In: SANTOS, E. O., \& SOUZA, M. (Orgs.). Teoria e prática do turismo no espaço rural, 60-79. Barueri, SP: Manole.

Silva, A. R.L., Machado, A. B., \& Catapan, A. H. (2014). Contribuição da comunicação digital na educação a distância: um mapeamento bibliométrico. In: BIEGING, P., \& BUSARELLO, R. I. (Orgs.). Interatividade nas TICs. São Paulo: Pimenta Cultura, cap. 9, 169-189. Recuperado em 02 de maio, 2017, de https://www.pimenta cultural.com/interatividade-nas-tics.

Silva, M. A. C., \& Souza, M. (2015). Motivações e benefícios socioeconômicos do turismo rural pedagógico para os empreendedores e a comunidade rural: o caso do Projeto Viva Ciranda e Roteiro Caminhos Rurais. Turismo: Visão e Ação, 17(3), 630-657.

Silva, M. R., Hayashi, C. R. M., \& Hayashi, M. C. P. I. (2011, junho). Análise bibliométrica e cientométrica: desafios para especialistas que atuam no campo. InCID: Revista de Ciência da 
Informação e Documentação. Ribeirão Preto, 2(1), 110-129. Recuperado em 02 de maio, 2017, de http://www.revistas.usp.br/incid/ article/view/42337/46008.

Souza, M., Elesbão, I., \& Schaidhauer, M. (2011). Os benefícios do turismo rural: caminhos de pedra. Rosa dos Ventos - Turismo e Hospitalidade, 3(2), 216-227. Bento Gonçalves, RS.

Tulik, Olga.(2003). Turismo rural. (2a. ed.). São Paulo: Aleph, (Coleção ABS do Turismo). 